\title{
EpCAM-specific CAR-expressing Autologous T-lymphocytes
}

National Cancer Institute

\section{Source}

National Cancer Institute. EpCAM-specific CAR-expressing Autologous T-lymphocytes. NCl Thesaurus. Code C126801.

A preparation of autologous T-lymphocytes that have been genetically modified to express a chimeric antigen receptor (CAR) specific for the antigen epithelial cell adhesion molecule (EpCAM), with potential immunostimulating and antineoplastic activities. Upon administration, the EpCAM-specific CAR-expressing autologous T-lymphocytes specifically recog nize and bind to EPCAM-expressing tumor cells, resulting in tumor cell lysis. EpCAM, a cell surface protein, is expressed by a variety of tumor cells. 